'Городская клиническая больница №52 Департамента здравоохранения города Москвы, Москва, Россия ${ }^{2}$ Московский государственный медико-стоматологический университет им. А.И. Евдокимова, Москва, Россия

Жировая ткань является эндокринным органом, синтезирующим большое количество биологически активных веществ - адипоцитокинов, влияющих на инсулинорезистентность (ИР), метаболизм глюкозы и липидов, процессы ангиогенеза и воспаления. Данные многочисленных исследований показывают тесную связь дисбаланса адипоцитокинов, формирующегося при избыточном отложении жировой ткани, с развитием сахарного диабета 2 типа и сердечно-сосудистых заболеваний. В статье представлен обзор современной литературы, обобщающий данные о воздействии адипоцитокинов на печень, скелетные мышцы, жировую ткань, эндотелиальные клетки и процессы воспаления, а также представлена попытка дефиниции термина «адипоцитокины» и классификации адипоцитокинов с позиции их влияния на метаболические сдвиги и провоспалительный статус. Представители адипоцитокинов (адипонектин, оментин, лептин, резистин, фактор некроза опухоли-а и интерлейкин-6) разделены на две группы: адипоцитокины, снижающие ИР, и адипоцитокины, повышающие ИР.

КЛЮЧЕВЫЕ СЛОВА: жировая ткань; адипокины; адипоцитокины; инсулинорезистентность; воспаление.

\title{
ADIPOCYTOKINES: MODERN DEFINITION, CLASSIFICATION AND PHYSIOLOGICAL ROLE
}

\author{
(c) Tatyana N. Markova ${ }^{1,2 *}$, Nadezhda K. Mishchenko², Diana V. Petina'
}

${ }^{1}$ City Clinical Hospital №52, Moscow, Russia

${ }^{2}$ Moscow State University of Medicine and Dentistry named after A.I. Evdokimov, Moscow, Russia

Adipose tissue is an endocrine organ which produces a large number of secretory bioactive substances also known as adipocytokines affecting directly insulin resistance (IR), glucose and lipid metabolism, angiogenesis and inflammation. The studies show a close connection between the imbalance of adipocytokines formed as a result of excessive deposit of adipose tissue in the course of the development of type 2 diabetes mellitus and cardiovascular diseases. In the present review, we summarize current data on the effect of the adipocytokines on the liver, skeletal muscles, adipose tissue, endothelial cells and inflammatory processes, as well as attempt to define the term «adipocytokines» and classify adipocytokines according to their influence on metabolic processes and pro-inflammatory status. Some of adipocytokines (adiponectin, omentin, leptin, resistin, tumor necrosis factor-a and interleukin-6) are divided into two groups: adipocytokines reducing IR, and adipocytokines increasing IR.

KEYWORDS: adipose tissue; adipokines; adipocytokines; insulin resistance; inflammation.

\section{МЕТОДОЛОГИЯ ПОИСКА ИСТОЧНИКОВ}

В процессе написания статьи использовались следующие базы данных: www.elibrary.ru, www.ncbi.nlm.nih. gov/pubmed, www.clinicalTrials.gov, поисковая система Google. Поиск проводился по ключевым словам: жировая ткань, адипоцитокины, инсулинорезистентность, воспаление.

\section{ВВЕДЕНИЕ}

В течение последних двух десятилетий все большее внимание уделяется изучению жировой ткани как эндокринного органа, способного вырабатывать адипоцитокины - биологически активные вещества, синтезируемые жировой тканью и обладающие многочисленными метаболическими эффектами [1]. В данном определении есть несколько неточностей. Во-первых, практически все адипоцитокины вырабатываются не только жировой тканью, но и другими тканями, тогда, вероятно, термин «адипоцитокин» не в полной мере отражает действительность, во-вторых, необходимо провести некоторую дифференцировку между адипокинами и адипоцитокинами. Термин «адипоцитокин» признается не всеми учеными, поскольку цитокины - вещества, участвующие в иммуновоспалительных реакциях. Однако не все адипоцитокины обладают иммуномодулирующим действием [2]. На сегодня в научной литературе наряду с термином «адипоцитокин» выделяют понятие «адипокин». В настоящее время не разработаны четкие дефиниции данных терминов. Так, Н. Сао (2014) описывает адипоцитокины как вещества, синтезированные в жировой ткани вследствие взаимодействия между адипоцитами и иммунными клетками. Схема взаимодействия адипоцита и иммунных клеток, расположенных в жировой ткани, представлена на рисунке 1 [2]. 


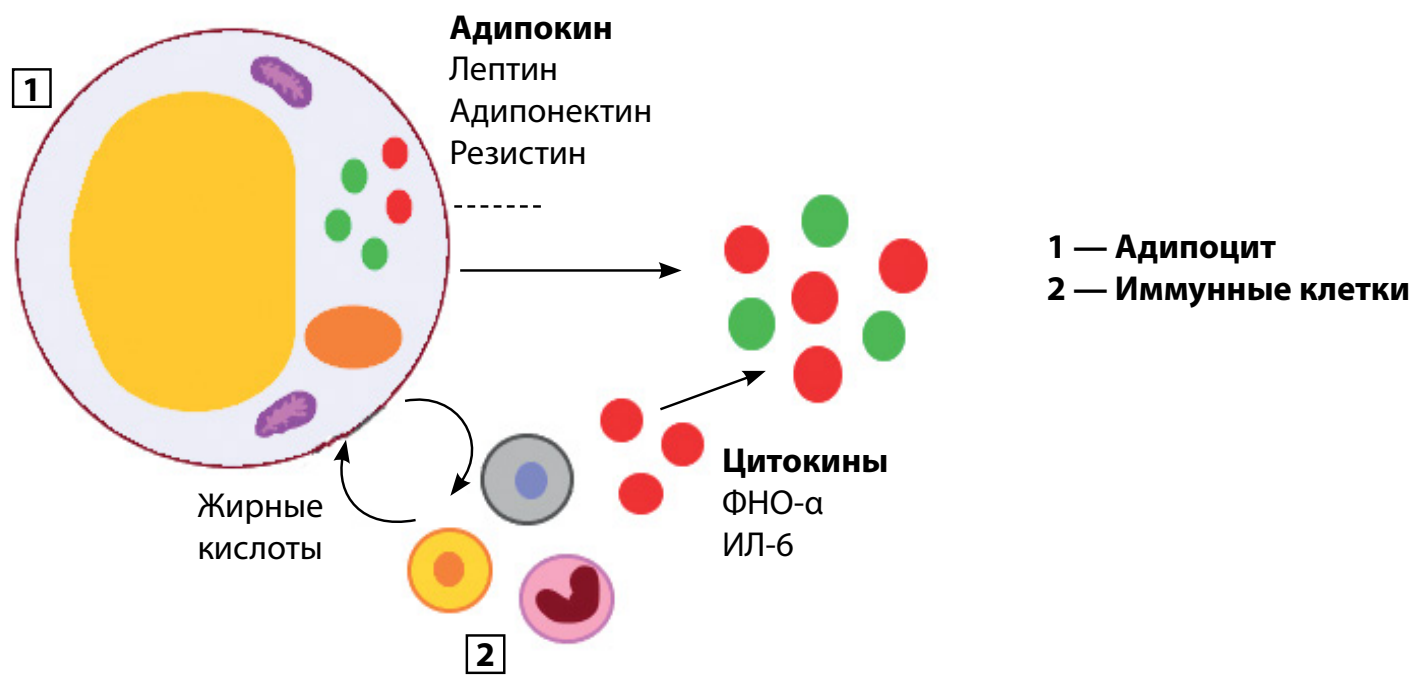

Рисунок. Схема взаимодействия адипоцита и иммунных клеток в жировой ткани [адаптировано 2].

В то же время Booth A. et al. (2015) не выделяют различий между терминами «адипоцитокин» и «адипокин» [3]. Следовательно, биологически активные вещества, продуцируемые жировой тканью, могут быть представлены как адипоцитокинами, так и адипокинами.

Современное представление о классификации адипоцитокинов основывается на их воздействии на клетки-мишени. Так, Ouchi N. et al. (2011) выделяют две группы адипоцитокинов: провоспалительные и противовоспалительные [4]. Согласно классификации Оh K.J. et al. (2016), адипоцитокины можно разделить на воспалительные, противовоспалительные и другие субстанции [5]. По данным литературы, лишь единичные статьи указывают на возможность классификации адипоцитокинов согласно месту их синтеза. Так, Чубриева С.Ю. и соавт. (2008) разделяют данные вещества на специфичные и неспецифичные для жировой ткани адипоцитокины [6].
В таблице 1 суммированы несколько классификаций адипоцитокинов.

В настоящем обзоре представлена классификация адипоцитокинов с позиции их влияния на инсулинорезистентность (ИР). Семь представителей адипоцитокинов разделены на две группы: адипоцитокины, снижающие ИР, и адипоцитокины, повышающие ИР. В 2005 г. Международная ассоциация диабета (IDF) выделила понятие ИР в качестве основного звена патогенеза метаболического синдрома (МС), включающего в себя абдоминальное ожирение, дислипидемию, нарушения углеводного обмена и артериальную гипертензию [7]. МС является фактором риска развития сахарного диабета 2 типа (СД2) и сердечно-сосудистых заболеваний (ССЗ). Изучение биологически активных веществ, снижающих или повышающих ИР, позволит разработать стратегии лечения данных заболеваний.

Таблица 1. Классификация адипоцитокинов

\begin{tabular}{|c|c|c|c|}
\hline Автор & Ouchi N. et al. [4] & Oh K.J. et al. [5] & Чубриева С.Ю. [6] \\
\hline \multirow[t]{3}{*}{ Группы } & $\begin{array}{l}\text { 1. Провоспалительные: } \\
\text { - лептин } \\
\text { - резистин } \\
\text { - ретинол-связывающий белок } \\
\text { - липокалин-2 } \\
\text { - ангиопоэтин-подобный белок-2 } \\
\text { - фактор некроза опухоли альфа } \\
\text { - интерлейкин-6 } \\
\text { - интерлейкин-18 } \\
\text { - хемокины (CCL2, CXCL5) } \\
\text { - висфатин }\end{array}$ & $\begin{array}{l}\text { 1. Провоспалительные: } \\
\text { - лептин } \\
\text { - резистин } \\
\text { - фактор некроза опухоли альфа } \\
\text { - интерлейкин-6 } \\
\text { - ретинол-связывающий белок }\end{array}$ & $\begin{array}{l}\text { 1. Специфичные для жировой } \\
\text { ткани: } \\
\text { - адипонектин } \\
\text { - лептин }\end{array}$ \\
\hline & $\begin{array}{l}\text { 2. Противовоспалительные: } \\
\text { - адипонектин } \\
\text { - секретируемый человеческий } \\
\text { протеин-5, родственный белкам } \\
\text { Frizzled }\end{array}$ & $\begin{array}{l}\text { 2. Противовоспалительные: } \\
\text { - адипонектин } \\
\text { - фактор роста фибробластов- } 21 \\
\text { - секретируемый человеческий } \\
\text { протеин-5, родственный белкам } \\
\text { Frizzled }\end{array}$ & $\begin{array}{l}\text { 2. Неспецифичные для жировой } \\
\text { ткани: } \\
\text { - ингибитор-1 активатора } \\
\text { плазминогена } \\
\text { - фактор некроза опухоли альфа }\end{array}$ \\
\hline & & $\begin{array}{l}\text { 3. Другие: } \\
\text { - иризин } \\
\text { - фетуин-А }\end{array}$ & \\
\hline
\end{tabular}




\section{АДИПОЦИТОКИНЫ, СНИЖАЮЩИЕ ИНСУЛИНОРЕЗИСТЕНТНОСТЬ}

К группе адипоцитокинов, снижающих ИР, отнесены адипонектин, оментин и лептин.

\section{АДИПОНЕКТИН}

Адипонектин представляет собой белок, состоящий из 244 аминокислот и имеющий коллагеноподобный участок. Данный адипоцитокин циркулирует в плазме крови в виде различных изоформ: низкомолекулярного тримера, среднемолекулярного гексамера и высокомолекулярного олигомера, среди которых биологически активной формой гормона является высокомолекулярный олигомер. В настоящее время получены данные, что адипонектин синтезируется не только адипоцитами жировой ткани, но и другими клетками, включая остеобласты, клетки паренхимы печени, миоциты, эпителиальные клетки и плацентарную ткань [8]. Адипонектин взаимодействует с двумя типа рецепторов: AdipoR1 и AdipoR2. AdipoR1 расположен во многих тканях организма, преимущественно в скелетных мышцах. AdipoR2 представлен главным образом в клетках печени [8]. С помощью данных рецепторов адипонектин оказывает многочисленные метаболические эффекты.

Так, в исследованиях показано, что под действием адипонектина в скелетных мышцах происходит усиление поглощения глюкозы, а также активируется процесс окисления жирных кислот. При изучении эффектов адипонектина на гепатоциты выявлено подавление процессов глюконеогенеза и гликогенолиза. Кроме того, адипонектин способен повышать активность карнитин-пальмитоилтрансферазы I и усиливать окисление жирных кислот в митохондриях клеток печени, одновременно уменьшая активность ключевых ферментов, участвующих в синтезе жирных кислот. Снижение уровня жирных кислот в гепатоцитах приводит к уменьшению ИР, так как триглицериды являются антагонистами инсулина [9].

Высокая экспрессия адипонектина отмечается не только в скелетных мышцах и печени, но и в жировой ткани. Благодаря своей аутокринной активности адипонектин способствует дифференцировке клеток адипоцитов, стимулирует адипогенез, повышает содержание липидов в адипоцитах, а также усиливает инсулин-направленный транспорт глюкозы [10]. Особый интерес представляет изучение влияния адипонектина на метаболические процессы у мышей, лишенных лептина, с гиперфагией (мыши ob/ob). В данном исследовании повышенный уровень адипонектина вызывал перераспределение триглицеридов из печени и мышечной ткани в жировую ткань, что улучшало чувствительность тканей к инсулину и приводило к нормализации уровня глюкозы крови и инсулина. Одновременно наблюдалось заметное улучшение метаболизма глюкозы в жировой ткани, сопровождающееся уменьшением количества макрофагов и снижением экспрессии фактора некроза опухоли альфа (TNFa). Кроме того, избыточная экспрессия адипонектина у мышей ob/ob приводила к увеличению количества подкожножировой клетчатки и усилению ее васкуляризации. В целом можно сделать вывод, что повышенное количество адипонектина приводит к массивному увеличению количества подкожножировой клет- чатки и предотвращает развитие ИР, обусловленное избыточным потреблением пищи [11].

Особый интерес представляет ассоциация уровня адипонектина и количества висцеральной жировой ткани. Так, известно, что концентрация данного адипоцитокина в сыворотке крови отрицательно коррелирует с количеством висцеральной жировой ткани [12]. По данным Reneau J., секреция адипонектина висцеральной жировой ткани уменьшается с увеличением степени ожирения, в то время как секреция изучаемого адипокина подкожно жировой клетчаткой остается неизменной, особенно у женщин. Это наблюдение может объяснить более низкие уровни циркулирующего адипонектина у лиц с центральным типом ожирения [13].

Важное значение имеет влияние адипоцитокина на поджелудочную железу. Так, результаты исследований показали, что введение адипонектина тучным мышам подавляет высвобождение инсулина при базальных концентрациях глюкозы и усиливает секрецию инсулина при ее повышенной концентрации. Также в опытах на мышах продемонстрирована способность адипонектина предотвращать апоптоз $\beta$-клеток поджелудочной железы, вызванный избыточным воздействием липидов и цитокинов [14].

Адипонектин оказывает влияние на сосудистый гомеостаз, воздействуя на важные сигнальные пути в эндотелиальных клетках и модулируя воспалительные реакции в субэндотелиальном пространстве. Влияние данного адипокина на сердечно-сосудистую систему частично опосредовано увеличением активности 5'-аденозинмонофосфат-активируемой протеинкиназы, что приводит к повышению концентрации оксида азота и предотвращает апоптоз эндотелиальных клеток. Также адипонектин препятствует активации эндотелиальных клеток после стимуляции провоспалительными веществами, такими, как TNFa и ядерный фактор каппа-в [15].

Таким образом адипонектин можно отнести к адипоцитокинам, снижающим ИР и обладающим противовоспалительным и антиатерогенным действиями. Благодаря описанным выше метаболическим эффектам, содержание данного адипокина исследуется у пациентов с СД2 [9, 16], СС3 [9] и ожирением [16].

\section{ОМЕНТИН}

Оментин (интелектин-1) - белок, состоящий из 313 аминокислотных остатков. Данное вещество вырабатывается преимущественно стромальными сосудистыми клетками висцеральной жировой ткани [17]. Также он может синтезироваться в эндотелиальных клетках, эпителиальных клетках кишечника [17], эпикардиальной жировой ткани, легких, яичниках и плаценте [18]. В настоящее время специфические рецепторы оментина не идентифицированы [19].

Висследованиях in vitro показано, что оментин повышает чувствительность адипоцитов человека к инсулину. Так, рекомбинантный оментин индуцировал фосфорилирование протеинкиназы В и усиливал стимулированное инсулином поглощение глюкозы как в подкожножировой клетчатке, так и в висцеральной жировой ткани [17]. Влияние оментина на скелетные мышцы до конца не изучено. Согласно данным литературы, в настоящее время не проведены крупные исследования, направленные на определение его 
функциональной роли в скелетных мышцах с использованием моделей грызунов или тканей человека [20].

Также большой интерес представляет влияние оментина на эндотелиальные клетки. В исследованиях определено снижение активности TNFa под влиянием оментина, что в дальнейшем приводит к уменьшению синтеза молекул адгезии [21, 22]. Кроме того, в опытах на крысах, страдающих СД2, выявлено улучшение эндотелиальной дисфункции под воздействием оментина [23]. Таким образом, оментин оказывает противовоспалительное действие на сосудистую стенку [22].

В исследованиях in vivo уровень оментина в плазме крови обратно коррелировал с индексом массы тела и показателями ИР, положительно - с содержанием адипонектина и холестерина липопротеинов высокой плотности. Таким образом, снижение уровня оментина связано с увеличением риска развития ожирения и ИР [24]. Также, по данным исследований, выявлена взаимосвязь между концентрацией оментина и нарушениями углеводного обмена и ССЗ. Так, достоверное снижение уровня оментина зафиксировано у пациентов с СД2 [25].

В целом оментин можно классифицировать как адипоцитокин, снижающий ИР. Однако необходимы дальнейшие исследования, уточняющие физиологическую роль оментина в углеводном обмене.

\section{ЛЕпТИн}

Лептин - белок, состоящий из 146 аминокислот [26]. Данный адипокин синтезируется преимущественно жировой тканью и в небольшом количестве слизистой дна желудка [27]. Структура лептина сходна по своему строению с провоспалительными цитокинами, такими как интерлейкин 6 (ИЛ-6) и гранулоцитарный колониестимулирующий фактор [26]. Лептин опосредует свои эффекты, связываясь со специфическими рецепторами (ObR), экспрессируемыми в головном мозге, а также в периферических тканях (нервной ткани, печени, поджелудочной железе, сердце и кишечнике) [28].

Главным органом-мишенью лептина служит дугообразное ядро гипоталамуса. Данное ядро играет важную роль в регулировании аппетита и энергетического гомеостаза. Нейроны дугообразного ядра содержат орексигенные (агути-подобный белок/нейропептид Y) и анорексигенные пептиды (проопиомеланокортин). Связывание лептина с нейронами дугообразного ядра приводит к высвобождению проопиомеланокортина и ингибированию выделения агути-подобного белка/нейропептида Ү, что вызывает снижение аппетита [28].

Лептин также воздействует на печень, скелетные мышцы и жировую ткань. Так, по результатам исследований обнаружено, что описанный белок ограничивает накопление триглицеридов в печени и скелетных мышцах. Кроме того, лептин модулирует функцию $\beta$-клеток поджелудочной железы. По мере увеличения массы тела повышенная выработка данного вещества приводит к предотвращению накоплению липидов в $\beta$-клетках. Также в исследованиях на животных показано, что лептин ингибирует секрецию инсулина поджелудочной железой [29]. Влияние лептина на сосудистую стенку до конца не изучено. В литературе имеются данные, сообщающие как о проангиогенном, так и об антиангиогенном действии описанного вещества [30].
Исследования, оценивающие роль лептина в иммунных реакциях, показали провоспалительное действие данного адипоцитокина [31]. Так, показано, что лечение лептином увеличивало выработку моноцитами цитокинов 1 типа, включая ИЛ-1, ИЛ-6 и TNFa, а также резистин [32].

Известным является факт, что у лиц с ожирением часто наблюдается лептинорезистентность. В ее основе лежат изменения транспорта лептина через гематоэнцефалический барьер, нарушение передачи сигнала от данного белка к рецепторам и, как следствие, снижение синтеза нейротрансмиттеров и нейромедиаторов в ответ на действие лептина. Ослабление чувствительности к описанному адипоцитокину в головном мозге приводит к избыточному накоплению триглицеридов в жировой ткани, а также в мышцах, печени и поджелудочной железе, что в конечном итоге нарушает секрецию инсулина [29].

Лептин подавляет потребление пищи и способствует расходованию энергии. Независимо от этих эффектов, лептин улучшает чувствительность периферических тканей (печени и скелетных мышц) к инсулину и модулирует функцию $\beta$-клеток поджелудочной железы. В большинстве случаев у пациентов с ожирением, несмотря на высокий уровень циркулирующего в кровеносном русле лептина, не происходит снижения веса, что отражает наличие лептинорезистентности [29].

В диагностическом плане лептин служит критерием диагностики редких форм ожирения. Так, согласно российским рекомендациям по лечению ожирения и коморбидных заболеваний, определение уровня данного адипоцитокина проводится при подозрении на моногенные формы ожирения [33].

\section{АДИПОЦИТОКИНЫ, ПОВЫШАЮЩИЕ ИНСУЛИНОРЕЗИСТЕНТНОСТЬ}

В группу адипоцитокинов, повышающих ИР, отнесены резистин, ретинол-связывающий протеин 4 (RBP4) и маркеры воспаления (TNFa, ИЛ-6).

\section{РЕЗИСТИН}

Резистин - низкомолекулярный белок, принадлежащий семейству резистиноподобных молекул. Первоначально данный адипоцитокин был выделен из жировой ткани, однако позже обнаружено, что основными источниками синтеза резистина являются макрофаги [34]. Резистин выявлен и в других органах и тканях: в костном мозге, легких, плаценте и $\beta$-клетках поджелудочной железы [35]. В настоящее время специфические рецепторы резистина не обнаружены [34].

В исследованиях на животных показано, что введение резистина мышам, страдающим ожирением, приводило к развитию нарушенной толерантности к глюкозе. В то же время уменьшение концентрации описываемого адипоцитокина снижало уровень глюкозы крови у мышей с ожирением и улучшало толерантность к глюкозе у здоровых животных. Данный белок снижал поглощение глюкозы скелетными мышцами независимо от активируемых инсулином сигнальных путей [36]. Кроме того, в опытах на крысах под влиянием резистина выявлено усиление активности апоптоза $\beta$-клеток поджелудочной железы при наличии инсулиномы [37]. Также показано, что описанный адипоци- 
токин в гепатоцитах крыс приводил к замедлению процессов гликогенеза и усилению гликогенолиза. Таким образом, содержание гликогена в печени уменьшалось [38].

В то же время влияние резистина на развитие гиперинсулинемии и ИР у людей до конца не изучено. В настоящее время в литературе имеются данные, свидетельствующие как о положительной корреляции между уровнями резистина и ожирением или ИР [39], так и об отсутствии изменений концентрации данного белка при ожирении, ИР и СД2 [40]. Однако большинство ученых описывают резистин как потенциальный фактор развития ИР и СД2. Так, показано, что специфические нуклеотидные полиморфизмы в гене RETN, кодирующем синтез резистина, вызывают ожирение, ИР и СД2 [41]. В исследованиях выявлен высокий уровень резистина в сыворотке крови у пациентов с ожирением и зафиксирована прямая корреляционная связь между уровнем данного адипоцитокина и массой жировой ткани [41].

Кроме влияния резистина на ИР, выявлены и другие эффекты описанного белка. Так, резистин принимает участие в процессах воспаления и дисфункции эндотелия $[41,42]$. Резистин обладает способностью активировать эндотелий, стимулируя высвобождение эндотелина-1, а также нарушает регуляцию молекул адгезии и хемокинов в сосудистых клетках [41]. Кроме того, отмечена способность резистина проявлять сильные провоспалительные свойства за счет активации секреции TNFa, ИЛ-6, ИЛ-12, моноцитарного хемотаксического протеина-1 через NF-kB-опосредованный путь [42].

В настоящее время резистин рассматривается как белок, усиливающий ИР. Данный адипоцитокин способен усугублять развитие клинических состояний, таких как ожирение, СД2 и СС3.

\section{РЕТИНОЛ-СВЯЗЫВАЮЩИЙ ПРОТЕИН 4 (RBP4)}

Ретинол-связывающий протеин 4 (RBP4) - белок, относящийся к семейству транспортных белков липокалинов и переносящий в кровеносном русле ретинол, известный как витамин А. Экспрессия данного вещества наиболее высока в печени, где содержится основное количество витамина А в организме. Однако RBP4 синтезируется в жировой ткани и в меньшем количестве в почках, пигментном эпителии сетчатки, яичках, легких и сосудистом сплетении желудочков головного мозга [43]. В настоящее время идентифицированы два рецептора RBP4 (STRA6 и RBPR2), которые опосредуют поглощение и высвобождение ретинола через клеточную мембрану $[43,44]$.

Основная биологическая роль RBP4 заключается в транспортировке ретинола из печени в органымишени [43]. Однако в литературе имеются данные, подтверждающие взаимосвязь между повышенным уровнем описанного белка и развитием ИР и СД2. Так, полиморфизм гена RBP4, приводящий к увеличению экспрессии RBP4 в жировой ткани [45], повышает риск развития СД2 у людей [46].

В настоящее время наиболее детально изучено влияние данного адипоцитокина на метаболизм глюкозы и липидов у животных. Так, искусственно индуцированное повышение уровня RBP4 вызывает резистентность к инсулину [47], а снижение концентрации данного ве- щества у тучных мышей улучшает чувствительность к инсулину [48]. Повышение уровня RBP4 увеличивает экспрессию основного фермента глюконеогенеза фосфоенолпируваткарбоксикиназы - в печени и нарушает действие инсулина в скелетных мышцах [47]. Гиперэкспрессия RBP4 в жировой ткани мышей приводит к активации липолиза с последующим высвобождением свободных жирных кислот в кровеносное русло, а также к усилению процессов воспаления в жировой ткани [49].

Исследования влияния RBP4 на маркеры ИР у людей ограничены. Так, в работе Kilicarslan M. et al. показано, что содержание RBP4 в печени, висцеральной жировой ткани и подкожной жировой клетчатке повышено у пациентов с морбидным ожирением. Концентрация RBP4 в кровеносном русле обратно коррелирует с инсулинозависимым подавлением липолиза и эндогенной продукцией глюкозы и утилизацией глюкозы периферическими тканями вследствие нарушения действия инсулина в скелетных мышцах. Кроме того, имеется связь между уровнями мPHK RBP4 и показателями мРHK маркеров воспаления в жировой ткани. Данный адипоцитокин оказывает свое действие прямо и косвенно через активацию макрофагов с помощью повышения уровня TNFa [50]. Также по результатам исследования Васюка Ю.А. и соавт. выявлено негативное влияние RBP4 на кардиометаболические риски у пациентов с артериальной гипертензией и ожирением [51].

Таким образом, RBP4 - не только белок, участвующий в транспорте ретинола, но и вещество, регулирующее обмен глюкозы и липидов, а также участник иммунных реакций.

\section{МАРКЕРЫ ВОСПАЛЕНИЯ}

Согласно данным литературы, при наличии ожирения отмечается значительная инфильтрация жировой ткани макрофагами, способными секретировать провоспалительные цитокины (TNFa, ИЛ-6 и другие). Кроме того, под действием TNFa преадипоциты начинают выработку провоспалительных цитокинов, способствуя дальнейшей активации макрофагов. Таким образом, формируется порочный круг, характеризующийся снижением чувствительности адипоцитов к инсулину [52].

\section{ФАКТОР НЕКРОЗА ОПУХОЛЕЙ АЛЬФА (TNFa)}

Фактор некроза опухолей альфа (TNFa) - провоспалительный цитокин, секретируемый преимущественно макрофагами [53]. По данным литературы известно, что TNFa снижает экспрессию инсулинозависимого транспортера глюкозы - ГЛЮТ-4, который локализуется в адипоцитах, скелетных мышцах и миокарде [54]. Кроме того, данный цитокин, индуцируя фосфорилирование серина в субстрате инсулинового рецептора-1, ингибирует действие инсулина [55]. В адипоцитах TNFa стимулирует липолиз, увеличивая уровень свободных жирных кислот [55]. Кроме того, TNFa обладает прямым провоспалительным эффектом в отношении сосудистых клеток, вызывая развитие дисфункции эндотелия [56].

Метаанализ исследований показал, что уровень TNFa в сыворотке крови значительно повышен как у пациентов с СД1, так и у лиц с СД2, что отражает высокий 
Таблица 2. Классификация адипоцитокинов в зависимости от основных эффектов

\begin{tabular}{|c|c|c|}
\hline Адипоцитокины & Метаболические эффекты & $\begin{array}{c}\text { Влияние на } \\
\text { воспалительный } \\
\text { процесс }\end{array}$ \\
\hline \multicolumn{3}{|c|}{ Снижающие ИР } \\
\hline Адипонектин & $\begin{array}{l}\text { - Подавление глюконеогенеза, гликогенолиза в печени } \\
\text { - Стимуляция окисления жирных кислот в печени и скелетных мышцах } \\
\text { - Стимуляция поглощения глюкозы в печени и скелетных мышцах } \\
\text { - Стимуляция секреции инсулина }\end{array}$ & Снижает \\
\hline Оментин & - Усиление поглощения глюкозы в адипоцитах & Снижает \\
\hline Лептин & $\begin{array}{l}\text { - Стимуляция окисления жирных кислот в печени, поджелудочной } \\
\text { железе и скелетных мышцах } \\
\text { - Модуляция функции } \beta \text {-клеток поджелудочной железы }\end{array}$ & Повышает \\
\hline \multicolumn{3}{|c|}{ Повышающие ИР } \\
\hline Резистин & $\begin{array}{l}\text { - Снижение захвата глюкозы скелетными мышцами, усиление } \\
\text { гликогенолиза, апоптоз } \beta \text {-клеток в опытах на животных }\end{array}$ & Повышает \\
\hline RBP4 & $\begin{array}{l}\text { - Снижение захвата глюкозы скелетными мышцами, усиление } \\
\text { глюконеогенеза, стимуляция липолиза в опытах на животных }\end{array}$ & Повышает \\
\hline TNFa & $\begin{array}{l}\text { - Модуляция действия инсулина в печени и скелетных мышцах } \\
\text { - Снижение захвата глюкозы скелетными мышцами, жировой тканью } \\
\text { - Стимуляция липолиза в жировой ткани }\end{array}$ & Повышает \\
\hline ИЛ-6 & $\begin{array}{l}\text { - Модуляция действия инсулина в печени и скелетных мышцах } \\
\text { - Снижение захвата глюкозы жировой тканью } \\
\text { - Стимуляция липолиза в жировой ткани }\end{array}$ & Повышает \\
\hline
\end{tabular}

Примечание: ИР — инсулинорезистентность; RBP4 - ретинол-связывающий протеин 4; TNFa — фактор некроза опухолей альфа; ИЛ-6 - интерлейкин-6.

провоспалительный статус при СД в целом и связь ИР с воспалением при СД2 $[57,58]$. Применение ингибиторов TNFa у лиц с метаболическим синдромом привело к снижению уровня гликемии натощак и повышению концентрации адипонектина [59]. Таким образом, TNFa играет важную роль в развитии ИР.

\section{ИНТЕРЛЕЙКИН-6 (ИЛ-6)}

Интерлейкин-6 (ИЛ-6) - цитокин, который синтезируется главным образом макрофагами [52]. В скелетных мышцах во время физических упражнений ИЛ-6 увеличивает поглощение глюкозы, что приводит к гипертрофии мышц, миогенезу и окислению жирных кислот, а также оказывает противовоспалительное действие [60]. В то время как В жировой ткани и печени данный белок усиливает ИР. Так, ИЛ-6 снижает индуцированное инсулином фосфорилирование субстрата инсулинового рецептора-1, вследствие чего тормозится захват глюкозы адипоцитами [60] и усиливается липолиз [55]. Также показано, что повышение концентрации ИЛ-6 наблюдается у пациентов с СД2 [60]. В целом, оценивая суммарное воздействие данного цитокина на биохимические процессы, ИЛ-б можно отнести к веществам, усиливающим ИР.

\section{ЗАКЛЮЧЕНИЕ}

Адипоцитокины - это биологически активные вещества, вырабатываемые преимущественно жировой тканью и другими тканями организма, влияющие на метаболические процессы, в первую очередь на жировой и углеводный обмены. На наш взгляд, все описанные в статье биологически активные вещества с учетом их влияния на воспалительный статус являются адипоцитокинами, поэтому нецелесообразно выделять отдельный термин «адипокины». С учетом их основных механизмов действия имеет смысл классифицировать адипоцитокины в группы в зависимости от влияния на метаболические эффекты и воспалительный процесс. Попытка суммировать эффекты адипоцитокинов представлена в таблице 2 .

Дальнейшие исследования, оценивающие физиологическую роль адипоцитокинов, помогут расширить диагностические критерии оценки уровня данных веществ в кровеносном русле и, возможно, позволят создать терапевтические средства для лечения патологических состояний, таких как ожирение, СД2 и ССЗ.

\section{ДОПОЛНИТЕЛЬНАЯ ИНФОРМАЦИЯ}

Источник финансирования. Работа выполнена по инициативе авторов без привлечения финансирования.

Конфликт интересов. Авторы декларируют отсутствие явных и потенциальных конфликтов интересов, связанных с содержанием настоящей статьи.

Участие авторов. Маркова Т.Н. - концепция и дизайн статьи, проверка статьи, внесение коррективов, утверждение рукописи; Мищенко Н.К. - дизайн статьи, сбор и обработка материалов, написание текста; Петина Д.В. - сбор и обработка материалов, написание текста. Все авторы одобрили финальную версию статьи перед публикацией, выразили согласие нести ответственность за все аспекты работы, подразумевающую надлежащее изучение и решение вопросов, связанных с точностью или добросовестностью любой части работы. 


\section{СПИСОК ЛИТЕРАТУРЫ | REFERENCES}

1. Дедов И.И., Мельниченко Г.А., Шестакова М.В., и др. Национальные клинические рекомендации по лечению морбидного ожирения у взрослых. 3-й пересмотр (лечение морбидного ожирения у взрослых) // Ожирение и метаболизм. 2018. - T. 15. — №1. - C. 53-70. [Dedov II, Mel'nichenko GA, Shestakova MV, et al. Russian national clinical recommendations for morbid obesity treatment in adults. 3rd revision (Morbid obesity treatment in adults). Obesity and metabolism. 2018;15(1):53-70. (In Russ.)]. doi: https://doi.org/10.14341/omet2018153-70

2. Cao H. Adipocytokines in obesity and metabolic disease. J Endocrinol. 2014;220(2):47-59. doi: https://doi.org/10.1530/JOE-13-0339

3. Booth A, Magnuson A, Fouts J, et al. Adipose tissue, obesity and adipokines: role in cancer promotion. Hormone Molecular Biology and Clinical Investigation. 2015;21(1):57-74. doi: https://doi.org/10.1515/hmbci-2014-0037

4. Ouchi N, Parker JL, Lugus JJ, et al. Adipokines in inflammation and metabolic disease. Nat Rev Immunol. 2011;11(2):85-97. doi: https://doi.org/10.1038/nri2921

5. Oh KJ, Lee DS, Kim WK, et al. Metabolic Adaptation in Obesity and Type II Diabetes: Myokines, Adipokines and Hepatokines. Int J Mol Sci. 2016;18(1):8. doi: https://doi.org/10.3390/ijms18010008

6. Чубриева С.Ю., Глухов Н.В., Зайчик А.М. Жировая ткань как эндокринный орган // Вестник Санкт-Петербургского университета. - 2008. - №1. - C. 32-44. [Chubrieva SJu, Gluhov NV, Zajchik AM. Adipose tissue as endocrine organ. Vestnik of Saint Petersburg University. 2008;(1):32-44 (In Russ.)].

7. Alberti KG, Zimmet P, Shaw J. Metabolic syndrome - a new world-wide definition. A Consensus Statement from the International Diabetes Federation. Diabet Med. 2006;23(5):469-480. doi: https://doi.org/10.1111/j.1464-5491.2006.01858.x

8. Achari AE, Jain SK. Adiponectin, a Therapeutic Target for Obesity, Diabetes, and Endothelial Dysfunction. Int J Mol Sci. 2017;18(6):1321. doi: https://doi.org/10.3390/ijms18061321 9

9. Khoramipour K, Chamari K, Hekmatikar AA, et al. Adiponectin: Structure, Physiological Functions, Role in Diseases, and Effects of Nutrition. Nutrients. 2021;13(4):1180. doi: https://doi.org/10.3390/nu13041180

10. Fu Y, Luo N, Klein RL, et al. Adiponectin promotes adipocyte differentiation, insulin sensitivity, and lipid accumulation. J. Lipid Res. 2005;46:1369-1379. doi: https://doi.org/10.1194/jlr.M400373-JLR200

11. Kim JY, Van De Wall E, Laplante M, et al. Obesity-associated improvements in metabolic profile through expansion of adipose tissue. J. Clin. Investig. 2007;117:2621-2637. doi: https://doi.org/10.1172/JCl31021

12. Kishida K, Funahashi T, Shimomura I. Adiponectin as a routine clinica biomarker. Best Pract Res Clin Endocrinol Metab. 2014;28(1):119-130. doi: https://doi.org/10.1016/j.beem.2013.08.006

13. Reneau J, Goldblatt M, Gould J, et al. Effect of adiposity on tissuespecific adiponectin secretion. PLoS One. 2018;13(6):e0198889. doi: https://doi.org/10.1371/journal.pone.0198889

14. Stern JH, Rutkowski JM, Scherer PE. Adiponectin, Leptin, and Fatty Acids in the Maintenance of Metabolic Homeostasis through Adipose Tissue Crosstalk. Cell Metab. 2016;23(5):770-784. doi: https://doi.org/10.1016/j.cmet.2016.04.011

15. Sowka, A, Dobrzyn P. Role of Perivascular Adipose Tissue-Derived Adiponectin in Vascular Homeostasis. Cells. 2021;10(6):1485. doi: https://doi.org/10.3390/cells10061485

16. Nguyen TMD. Adiponectin: Role in Physiology and Pathophysiology. Int J Prev Med. 2020;11:136. doi: https://doi.org/10.4103/ijpvm.IJPVM_193_20

17. Yang RZ, Lee MJ, Hu H, et al. Identification of omentin as a novel depot-specific adipokine in human adipose tissue: possible role in modulating insulin action. Am J Physiol Endocrinol Metab. 2006;290:E1253-E1261. doi: https://doi.org/10.1152/ajpendo.00572.2004

18. Halabis M, Dziedzic M, Warchulinska J, et al. Omentin - a new adipokine with many roles to play. Curr Issues Pharm Med Sci. 2015;28(3):176-180. doi: https://doi.org/10.1515/cipms-2015-0067

19. Zhou Y, Zhang B, Hao C, et al. Omentin-A Novel Adipokine in Respiratory Diseases. Int J Mol Sci. 2017;19(1):73. doi: https://doi.org/10.3390/ijms19010073

20. Nicholson T, Church C, Baker DJ, et al. The role of adipokines in skeletal muscle inflammation and insulin sensitivity. J Inflamm (Lond). 2018;15:9. doi: https://doi.org/10.1186/s12950-018-0185-8
21. Zhong X, Li X, Liu F, et al. Omentin inhibits TNF-a-induced expression of adhesion molecules in endothelial cells via ERK/NF-KB pathway. Biochem Biophys Res Commun. 2012;425(2):401-406. doi: https://doi.org/10.1016/j.bbrc.2012.07.110.

22. Kazama K, Usui T, Okada M, et al. Omentin plays an antiinflammatory role through inhibition of TNF-a-induced superoxide production in vascular smooth muscle cells. European journal of pharmacology. 2012;686(1-3):116-123. doi: https://doi.org/10.1016/j.ejphar.2012.04.033

23. Leandro A, Queiroz M, Azul L, et al. Omentin: A novel therapeutic approach for the treatment of endothelial dysfunction in type 2 diabetes. Free Radic Biol Med. 2021;162:233-242. doi: https://doi.org/10.1016/j.freeradbiomed.2020.10.021

24. Celia M. de Souza Batista, Rong-Ze Yang, Mi-Jeong Lee, et al. Omentin Plasma Levels and Gene Expression Are Decreased in Obesity. Diabetes. 2007:56(6):1655-1661. doi: https://doi.org/10.2337/db06-1506

25. Вербовой А.Ф., Соломонова Е.С., Пашенцева Ф.В. Лептин, резистин и оментин у пациентов с нарушенной толерантностью к глюкозе и сахарным диабетом 2-го типа // Известия ВУзов. Поволжский регион. Медицинские науки. - 2012. - №3. - C. 52-59. [Verbovoj AF, Solomonova ES, Pashenceva FV. Leptin, resistin and omentin in patients with impaired glucose tolerance and type 2 diabetes mellitus. University proceedings. Volga Region. Medical sciences. 2012;3:52-59 (In Russ.)].

26. Peelman F, Zabeau L, Moharana K, et al. 20 years of leptin: Insights into signaling assemblies of the leptin receptor. Journal of Endocrinology. 2014;223(1):T9-T23. doi: https://doi.org/10.1530/JOE-14-0264

27. Cammisotto PG and Bendayan M. Leptin secretion by white adipose tissue and gastric mucosa. Histol Histopathol. 2007;22(2):199-210. doi: https://doi.org/10.14670/HH-22.199

28. Dornbush S, Aeddula NR. Physiology, Leptin. In: StatPearls. Treasure Island (FL): StatPearls Publishing; 2021.

29. Rabe K, Lehrke M, Parhofer KG, et al. Adipokines and insulin resistance. Mol Med. 2008;14(11-12):741-751. doi: https://doi.org/10.2119/2008-00058

30. Tahergorabi Z, Khazaei M. Leptin and its cardiovascular effects: Focus on angiogenesis. Adv Biomed Res. 2015;4:79. doi: https://doi.org/10.4103/2277-9175.156526

31. Kiernan $\mathrm{K}$, Maclver NJ. The Role of the Adipokine Leptin in Immune Cell Function in Health and Disease. Front Immunol. 2021;11. doi: https://doi.org/10.3389/fimmu.2020.622468

32. Tsiotra PC, Boutati E, Dimitriadis G, Raptis SA. High Insulin and Leptin Increase Resistin and Inflammatory Cytokine Production from Human Mononuclear Cells. Biomed Res Int. 2013;2013:1-10. doi: https://doi.org/10.1155/2013/487081

33. Дедов И.И., Шестакова М.В., Мельниченко Г.А., и др. Междисциплинарные клинические рекомендации «Лечение ожирения и коморбидных заболеваний» // Ожирение и метаболизм. - 2021. - T. 18. - №1. - C. 5-99. [Dedov II, Shestakova MV, Melnichenko GA, et al. Interdisciplinary clinical practice guidelines «Management of obesity and its comorbidities». Obesity and metabolism. 2021;18(1):5-99. (In Russ.)]. doi: https://doi.org/10.14341/omet12714

34. Li Y, Yang Q, Cai D, et al. Resistin, a Novel Host Defense Peptide of Innate Immunity. Front Immunol. 2021;12. doi: https://doi.org/10.3389/fimmu.2021.699807

35. Pang SS, Le YY. Role of resistin in inflammation and inflammationrelated diseases. Cell Mol Immunol. 2006;3(1):29-34.

36. Moon B, Kwan JJ-M, Duddy N, et al. Resistin inhibits glucose uptake in L6 cells independently of changes in insulin signaling and GLUT4 translocation. Am. J. Physiol. Endocrinol. Metab. 2003;285(1):E106-115. doi: https://doi.org/10.1152/ajpendo.00457.2002

37. Gao C, Zhao D, Qiu J, et al. Resistin induces rat insulinoma cell RINm5F apoptosis. Mol. Biol. Rep. 2009;36:1703-1708. doi: https://doi.org/10.1007/s11033-008-9371-8.

38. Yang $Y$, Xiao M, Mao Y, et al. Resistin and insulin resistance in hepatocytes: resistin disturbs glycogen metabolism at the protein level. Biomed. Pharmacother. 2009;63:366-374 doi: https://doi.org/10.1016/j.biopha.2008.06.033

39. Azuma K, Katsukawa F, Oguchi S, et al. Correlation between serum resistin level and adiposity in obese individuals. Obes. Res. 2003;11:997-1001. doi: https://doi.org/10.1038/oby.2003.137 
40. Lee JH, Chan JL, Yiannakouris N, et al. Circulating Resistin Levels Are Not Associated with Obesity or Insulin Resistance in Humans and Are Not Regulated by Fasting or Leptin Administration: CrossSectional and Interventional Studies in Normal, Insulin-Resistant, and Diabetic Subjects. The Journal of Clinical Endocrinology \& Metabolism. 2003;88(10):4848-4856. doi: https://doi.org/10.1210/jc.2003-030519

41. Acquarone $\mathrm{E}$, Monacelli F, Borghi R, et al. Resistin: A reappraisal. Mech Ageing Dev. 2019;178:46-63. doi: https://doi.org/10.1016/j.mad.2019.01.004

42. Tripathi D, Kant S, Pandey S, et al. Resistin in metabolism, inflammation, and disease. FEBS J. 2020;287(15):3141-3149. doi: https://doi.org/10.1111/febs.15322

43. Steinhoff JS, Lass A, Schupp M. Biological Functions of RBP4 and Its Relevance for Human Diseases. Front Physiol. 2021;12. doi: https://doi.org/10.3389/fphys.2021.659977

44. Alapatt, P, Guo F, Komanetsky SM, et al. Liver retinol transporter and receptor for serum retinol-binding protein (RBP4). J Biol Chem. 2013;288(2):1250-65. doi: https://doi.org/10.1074/jbc.M112.369132

45. Munkhtulga L, Nagashima S, Nakayama K, et al. Regulatory SNP in the RBP4 gene modified the expression in adipocytes and associated with BMI. Obesity. 2010;18:1006-1014. doi: https://doi.org/10.1038/oby.2009.358

46. Van Hoek M, Dehghan A, Zillikens MC, et al. An RBP4 promoter polymorphism increases risk of type 2 diabetes. Diabetologia. 2008;51:1423-1428. doi: https://doi.org/10.1007/s00125-008-1042-8

47. Yang $Q$, Graham TE, Mody N, et al. Serum retinol binding protein 4 contributes to insulin resistance in obesity and type 2 diabetes. Nature. 2005;436:356-362. doi: https://doi.org/10.1038/nature03711

48. Ma X, Zhou Z, Chen Y, et al. RBP4 functions as a hepatokine in the regulation of glucose metabolism by the circadian clock in mice. Diabetologia. 2016;59:354-362 doi: https://doi.org/10.1007/s00125-015-3807-1

49. Lee $\mathrm{SA}$, Yuen JJ, Jiang $\mathrm{H}$, et al. Adipocytespecific overexpression of retinol-binding protein 4 causes hepatic steatosis in mice. Hepatology. 2016;64:1534-1546. doi: https://doi.org/10.1002/hep.28659

50. Kilicarslan M, de Weijer BA, Simonyté Sjödin K, et al. RBP4 increases lipolysis in human adipocytes and is associated with increased lipolysis and hepatic insulin resistance in obese women. FASEB J. 2020;34(5):6099-6110. doi: https://doi.org/10.1096/fj.201901979RR.

51. Васюк Ю.А., Садулаева И.А., Ющук Е.Н., и др. Ретинолсвязывающий белок как маркер сердечно-сосудистого риска у пациентов с артериальной гипертензией и ожирением // Российский кардиологический журнал. 2018. - T. 4. — №156. - C. 14-18. [Vasyuk YuA, Sadulaeva IA Yushchuk EN, et al. Retinol Binding protein as a marker of cardiovascular risk in arterial hypertension and obesity. Russian Journal of Cardiology. 2018;4(156):14-18 (In Russ.)]. doi: https://doi.org/10.15829/1560-4071-2018-4-14-18

52. $\mathrm{Xu} \mathrm{H}$, Barnes $\mathrm{GT}$, Yang $\mathrm{Q}$, et al. Chronic inflammation in fat plays a crucial role in the development of obesity-related insulin resistance. J Clin Invest. 2003;1 12(12):1821-1830. doi: https://doi.org/10.1172/JCl19451

53. Locksley RM, Killeen N, Lenardo MJ. The TNF and TNF receptor superfamilies: integrating mammalian biology. Cell. 2001;104(4):487-501 doi: https://doi.org/10.1016/s0092-8674(01)00237-9.

54. Akash MSH, Rehman K, Liaqat A. Tumor necrosis factor-alpha: role in development of insulin resistance and pathogenesis of type 2 diabetes mellitus. Journal of Cellular Biochemistry. 2018;119(1):105-110. doi: https://doi.org/10.1002/jcb.26174

55. Foley KP, Chen Y, Barra NG, et al. Inflammation promotes adipocyte lipolysis via IRE1 kinase. J Biol Chem. 2021;296:100440. doi: https://doi.org/10.1016/j.jbc.2021.100440

56. Wang B, Chen R, Gao H, et al. A comparative study unraveling the effects of TNF-a stimulation on endothelial cells between 2D and 3D culture. Biomed Mater. 2020;15(6):065018. doi: https://doi.org/10.1088/1748-605X/ab95e3

57. Qiao Y, Chen Y, Pan Y, et al. The change of serum tumor necrosis factor alpha in patients with type 1 diabetes mellitus: A systematic review and meta-analysis. PLoS One. 2017;12(4):e0176157. doi: https://doi.org/10.1371/journal.pone.0176157

58. Liu C, Feng X, Li Q, et al. Adiponectin, TNF-a and inflammatory cytokines and risk of type 2 diabetes: a systematic review and meta-analysis. Cytokine. 2016;86:100-109. doi: https://doi.org/10.1016/j.cyto.2016.06.028

59. Stanley TL, Zanni MV, Johnsen S, et al. TNF-alpha antagonism with etanercept decreases glucose and increases the proportion of high molecular weight adiponectin in obese subjects with features of the metabolic syndrome. J Clin Endocrinol Metab. 2011;96(1):E146-150. doi: https://doi.org/10.1210/jc.2010-1170

60. Piya MK, McTernan PG, Kumar S. Adipokine inflammation and insulin resistance: the role of glucose, lipids and endotoxin. J Endocrinol. 2013;216(1):T1-T15. doi: https://doi.org/10.1530/JOE-12-04

Рукопись получена: 21.08.2021. Одобрена к публикации: 06.12.2021. Опубликована online: 28.02.2022.

ИНФОРМАЦИЯ ОБ АВТОРАХ [AUTHORS INFO]

* Маркова Татьяна Николаевна, д.м.н., профессор [Tatyana N. Markova, MD, PhD, Professor]; адрес: Россия, 123182, Москва, ул. Пехотная, д. 3 [address: 3 Pehotnaja street, 123182 Moscow, Russian Federation]; ORCID: https://orcid.org/0000-0002-8798-887X; SPIN-код: 5914-2890; e-mail: markovatn18@yandex.ru

Мищенко Надежда Константиновна, аспирант, врач-эндокринолог [Nadezhda K. Mishchenko, PhD student, endocrinologist]; ORCID: https://orcid.org/0000-0001-8270-5626; SPIN-код: 1975-9680; e-mail: mischencko.nadejda2015@ yandex.ru

Петина Диана Викторовна, врач-эндокринолог [Diana V. Petina, endocrinologist]; ORCID: https://orcid.org/0000-0002-6603-5041; SPIN-код: 7224-3114; e-mail: doctor_di93@mail.ru

\section{ЦИТИРОВАТЬ:}

Маркова Т.Н., Мищенко Н.К., Петина Д.В. Адипоцитокины: современный взгляд на дефиницию, классификацию и роль в организме // Проблемы эндокринологии. — 2022. — Т. 68. — №1. — C. 73-80. doi: https://doi.org/10.14341/probl12805

\section{TO CITE THIS ARTICLE:}

Markova TN, Mishchenko NK, Petina DV. Adipocytokines: modern definition, classification and physiological role. Problems of Endocrinology. 2022;68(1):73-80. doi: https://doi.org/10.14341/probl12805 